\title{
USING SOFT PRECEDENCE RELATIONS FOR REDUCTION OF THE CONSTRUCTION PROJECT DURATION
}

\author{
Piotr Jaskowski ${ }^{1}$, Anna Sobotka ${ }^{2}$ \\ ${ }^{1}$ Faculty of Civil Engineering and Architecture, Lublin University of Technology, \\ ul. Nadbystrzycka 40, 20-618 Lublin, Poland \\ ${ }^{2}$ Faculty of Mining and Geoengineering, AGH University of Science and Technology, \\ al. Mickiewicza 30, 30-059 Krakow, Poland \\ E-mails: ${ }^{1}$ p.jaskowski@pollub.pl (correspondingauthor); ${ }^{2}$ sobotka@agh.edu.pl
}

Received 06 February 2011; accepted 21 August 2011

\begin{abstract}
Current network techniques used for project scheduling presume that there is only one logical sequence of activities. However, in reality, the precedence logic of activities is not necessarily unchangeable. There are two types of relations between activities: fixed (hard) and soft. Current scheduling methods do not differentiate between these two types of relations and require a planner to choose one particular logical sequence based on some assumptions. The paper presents a model that allows for "weakening" the links between activities, i.e. that permits concurrent execution of activities or reversing their order, but this may require additional resource-consuming works or expenditures. The model involves two subtypes of soft logic: REVERSED and CANCELED to represent the soft relations between activities. Its mathematical form is a mixed linear integer programming model of minimizing the project duration without exceeding the allowed budget. The paper presents an example of practical application of the method to scheduling interior finishing works. The results support the argument that using soft logic relations between construction activities provides more flexibility in reducing project duration, activities timing and resource allocation.
\end{abstract}

Keywords: construction planning, scheduling, network analysis, time-cost tradeoff, soft logic.

Reference to this paper should be made as follows: Jaskowski, P.; Sobotka, A. 2012. Using soft precedence relations for reduction of the construction project duration, Technological and Economic Development of Economy 18(2): 262-279.

JEL Classification: C02, C41, C61, M11. 


\section{Introduction}

The problem of reducing duration of construction projects is twofold: it occurs at planning stage, when the project stakeholders usually strive for minimizing duration for economical reasons, and at the construction stage, when the contractor needs to take measures to reduce the impact of unforeseen circumstances. Speed as a competitive factor is gaining more and more importance for companies involved in global market competition (Sapkauskiene, Leitoniene 2010). The delay of building projects is still a common problem (Lin et al. 2011). Paslawski (2008) proposed to increase flexibility of construction process engineering, based on creating multiple variants for process realization options, thus enabling adaptation to current realization conditions. According to Tamimi and Diekmann (1988), one of the most important functions of planning is to offset uncertainty and change. The building industry is characterised by high variety and variability of working processes and work environment conditions (Boguslauskas, Adlyte 2010; Hola 2010; Jaskowski, Biruk 2011; Zavadskas et al. 2010c), which result in time delay, cost overrun, quality defects, and other negative impacts (Enshassi et al. 2010). The risk in construction business is very high (Zavadskas et al. 2010c). Risk comes from many sources during the whole project life cycle (Enshassi et al. 2010; Klimov, Merkuryev 2008; Shevchenko et al. 2008; Manik et al. 2008; Kaplinski, Janusz 2006; Karlowski, Paslawski 2008). The problem of decision-making in risk environment (Peldschus 2008; Kahraman, Kaya 2010; Kapliński, Tamošaitienė 2010; Ginevičius, Zubrecovas 2009; Vlasenko, Kozlov 2009; Zavadskas et al. 2010a, 2010b), and risk handling (e.g. Perera et al. 2009; Kheirkhah et al. 2009; Jaskowski et al. 2010) attract the interest of numerous researchers and practitioners. Risk is evaluated with the purpose to avoid the loss in business activities (Pridotkiene, Dapkus 2011). If the project does not progress exactly as planned, its schedule has to be updated and actions are to be taken to speed up the remaining activities. Usually, this involves additional expenses. This time-cost tradeoff problem has been studied extensively since the development of the critical path method (CPM) in the late 50s. Another way is to reconstruct the original network model by changing the sequence or even the nature (construction method, design solution) of activities to maintain a practicable program and meet the project deadlines.

Network techniques have been widely implemented for construction project planning. However, they usually presume that there is only one logical sequence of the activities in a project. In practice, relations between activities are not necessarily unchangeable. The current popular scheduling models do not account for this fact, and thus the analysis is being performed as if all relations were firm. If a project did not progress exactly as planned, its original project network would have to be rebuilt manually. Manual modifications are inevitably laborious and time-consuming.

The paper analyses the problem of choosing corrective measures to reduce the project duration and, at the same time, to keep the costs within budget. A mathematical model of the problem has been created and equipped with additional precedence relations, varying from those used in traditional scheduling methods. A simple example has been presented to demonstrate the method. 


\section{Methods of reducing project duration}

The project management literature presents many methods of planning aimed at reducing project duration. Some of them are:

1. Introducing assembly line approach and a steady rhythm of work of crews (dividing the project scope into units of similar labor consumption, breaking down complex activities into simple repetitive ones that may be executed by specialized crews, provide continuity of work of these crews so that they move from one location (unit) to the other and not interrupt the work of other specialized crews) (Biruk, Jaskowski 2008; Fan, Tserng 2006; Harris, Ioannou 1998; Reda 1990; Russel, Wong 1993);

2. Reducing the duration of activities by adding more resources and solving time-cost tradeoff problems using linear (Elmaghraby, Salem 1984; Fulkerson 1961; Kelley 1961; Siemens 1971), or non-linear (Elmaghraby, Salem 1982; Falk, Horowitz 1972; Lamberson, Hocking 1970) continuous activity cost functions; there have also been discrete models of time-cost trade-off, i.e. considering a number of possible construction methods (multiple processes modes) to accomplish a construction process (De et al. 1995). Moussourakis and Haksever (2004) presented a mixed integer-programming model with nonlinear, discrete and piecewise discontinuous activity time-cost function. To solve the discrete large-scale practical problems, metaheuristic procedures have been used (Jaskowski, Sobotka 2006; Sakellaropoulos, Chassiakos 2004; Zheng et al. 2004). Yang (2007) used the particle swarm optimization algorithm to solve this complex problem;

3. Changing activities precedence relations:

a) planning activities to be executed in parallel if possible from the point of construction methods and space constraints (Maheswari et al. 2006);

b) reversing activity sequence (Moussorakis, Haksever 2004; Liberatore, PollackJohnson 2006; Wang 2005);

4. Combination of the above (Chassiakos, Sakellaropoulos 2005; Fan, Tserng 2006).

\section{Soft logic concept}

Traditional methods of project scheduling are based on network models with fixed activity sequence. The precedence links between activities (mandatory and discretionary relations) represent constraints of space, construction methods, project logic and assumptions on resource availability.

In fact, these relations may be of "hard" or "soft" character. Mandatory relations are those inherent in the nature of the work being done. They often involve physical limitations. Constraints defined by mandatory relations are called hard-logic. For instance, it is impossible to start concreting a structural element before its formwork is done and reinforcement put in the right place - the relations between activities: "assemble formwork" and "place concrete" are hard and their sequence cannot be changed. 
Discretionary dependencies between activities are those that are defined arbitrarily by the project management team on the basis of their own experience or the profession or industry "best practices". Constraints caused by discretionary dependencies are called soft logic. An example of soft relation may be "put floor screed after walls have been plastered" (assumed by the planner) - it is physically possible to reverse the sequence (i.e. "weaken" the predefined relation). Changing the sequence of activities may require additional works (as e.g. covering screeds with plastic foil before plastering to avoid damage), which increases time and financial outlays. If a precedence relation between two activities resulted from availability of resources, the planner might wish to consider procuring more resources (e.g. machines or workforce) to be able to run the activities in parallel - which would involve certain additional costs. However, "weakening" a precedence relation may be more efficient than changing construction methods or processes modes (with lower labor-consumption or higher resources demand).

A similar problem was considered by Liberatore and Pollack-Johnson (2006), who assumed a linear relationship between time and cost of activities, and a possibility of eliminating some precedence relations or executing activities in parallel; in the latter case, the cost of additional works was modeled in proportion to the difference between activities' starting times.

The idea of soft relations is not new. For instance, alternative network models (GERT) enable the planner to model variants of projects whose scope and structure is not fully determined by means of three types of nodes: AND, EXCLUSIVE-OR and INCLUSIVE. In the field of construction, they were applied for planning repair works.

Tamimi and Diekmann (1988) developed the SOFTCPM method that allowed for soft relations to update network models in the case that there was a possibility to change activity sequence. The initial and updated activity sequences are established taking into account the external factors (constraints), such as limited resources. This results in a limitation of the total number of activities that can be done at the same time. The additional cost and/or works connected with changing the sequence of processes is not considered, so the model does not guarantee that the optimal schedule (in terms of both duration and costs) will be found. El-Sersy (cited by Wang 2005) adopted some of the terminology associated with GERT to develop three types of soft links: OR (that allows running the activities in parallel), EXLUSIVE-OR (that allows reversing sequence) and SOFT (that allows canceling the relation). However, the reference to GERT and use of similar terms to describe relations seems confusing as they have a different interpretation.

Wang (2005) examined the impact of soft relations on the duration of construction projects in stochastic conditions. The research reveals that the results are close to those obtained with PERT. Nevertheless, he assumes that the original predecessors and successors of activities do not change, when soft links are ignored. Fan et al. (2003) proposed Object-Oriented Evaluation and Review Technique (OERT) - a scheduling technique that uses heuristic sequencing principle "the activity which can start shall start first" and priority rule. The heuristic approach allows only to find suboptimal solutions in terms of project duration. Fan and Tserng (2006), utilizing the soft logic sequencing principles used in OERT, developed also a computer system which provides the shortest duration logic and the start and finish dates required to maintain work continuity in repetitive projects. Koo et al. (2007) presented a formal identification 
and resequencing process that supports rapid development of sequencing alternatives in construction schedules to expedite milestone or bottleneck activities. The process builds on a constraint ontology that provides domain-specific representation of sequencing rationale for construction activities.

\section{Proposed approach - mathematical model}

A construction project can be modeled as an activity on node network. Precedence relations between activities are modeled by a graph $G=\langle V, E\rangle$, directed and acyclic with a single dummy initial node and a single dummy final node, where $V=\{0,1,2, \ldots, n\}$ is a set of activities, the edges (or arcs) $E \subset V \times V$ represent precedence relations between activities. The set $E$ comprises two disjoint subsets of relations: $H$ - a set of hard relations and related graph arcs, and $S$ - a set of soft relations $(H \cup S=E, H \cap S=\varnothing)$. The set $S$ consists of two disjoint subsets: $S R$ with REVERSED-type links (allowing processes to run in reversed order) and $S C$ with CANCELED-type links (which can be canceled, allowing processes to run in parallel).

The soft relations are intended to represent mainly the construction method-related sequence of processes. REVERSED-type links allow processes to run in reversed order. Exercising the option of weakening the originally specified precedence relation between activities causes usually additional work and/or costs. Some examples of REVERSED-type precedence are presented in the previous section, and they seem to be more frequent in real life conditions than CANCELED-type links. CANCELED-type link allow processes to run parallel in certain circumstances. They do not represent constraints of construction methods, and are rather a result of limited space or resource availability. For example an additional process may be entrusted to a resource already busy with some process done in a limited space. This additional process cannot be completed by other resources for the lack of space. Of course, this would increase the completion time of the main task, but not necessarily by the full time needed for the additional task: if the additional task was fitted into some lags necessary in the delivery of the main task that in other case would be idle time for the resource considered. The possibility of introducing a CANCELED-type link occurs thus in the case that, for the resource limitations, the processes are planned to run in series, but when some additional resources occur to be available, it is possible to run the processes in parallel. The CANCELEDtype link may be used for considering the following: instead of entrusting two consecutive tasks to the same resource, an additional resource (subcontractor) can be employed for the second task and the first and the second task can be done at once. This is of course related with paying more (for employing the additional resource or in terms of lost opportunity cost related with not providing work to the resources we have already employed).

While modeling a project by a graph, it should be assured that each activity (except the first and the last one) has a predecessor and a successor even if a soft relation was to be weakened - so to assure that each activity stays in a path that links the start and the end nodes. The planner should consider an option of weakening relations, changing the sequence of activities and introducing additional relations. Let us consider an example presented in Figure 1. In the case of the soft precedence relation between activities $k$ and $l$ it should be analyzed which of the predecessors of the activity $k$ condition also the start of the activity $l$, and if $k$ conditions 
also a start of any successors of the activity $l$. The model is to be augmented by the additional relations identified. Figure 1 presents two such additional links. Activity $l$ can start after $c$ has been finished, and $x$ can start after $k$ has been finished. It is worth considering, that if these relations were omitted in the model illustrated on Figure 1a and if the relation $(k, l) \in S$ was weakened (Fig. 1b), then activity $l$ would have no predecessor (it could theoretically start as the project starts), and $x$ could be performed in parallel with $k$.

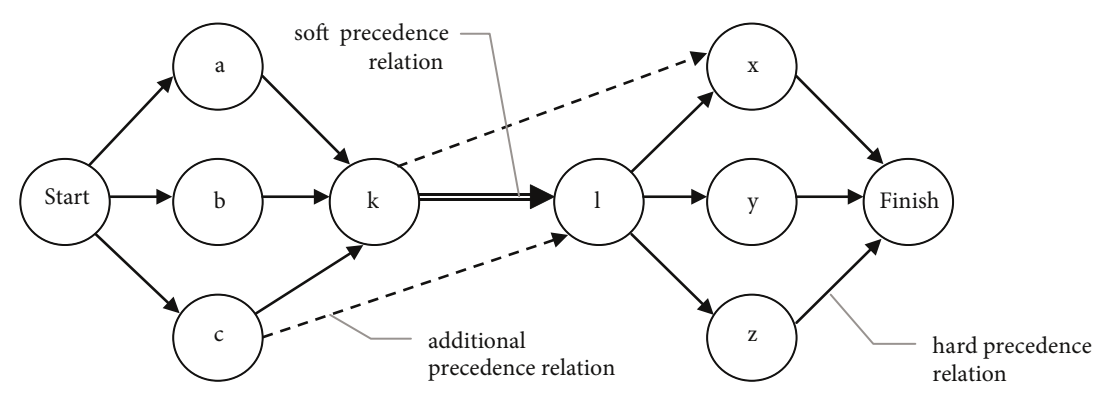

a) The project schedule before weakening the soft precedence relation

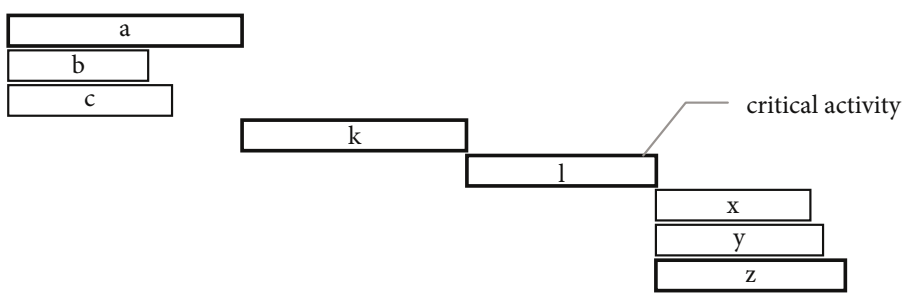

b) The project schedule after weakening the soft precedence relation

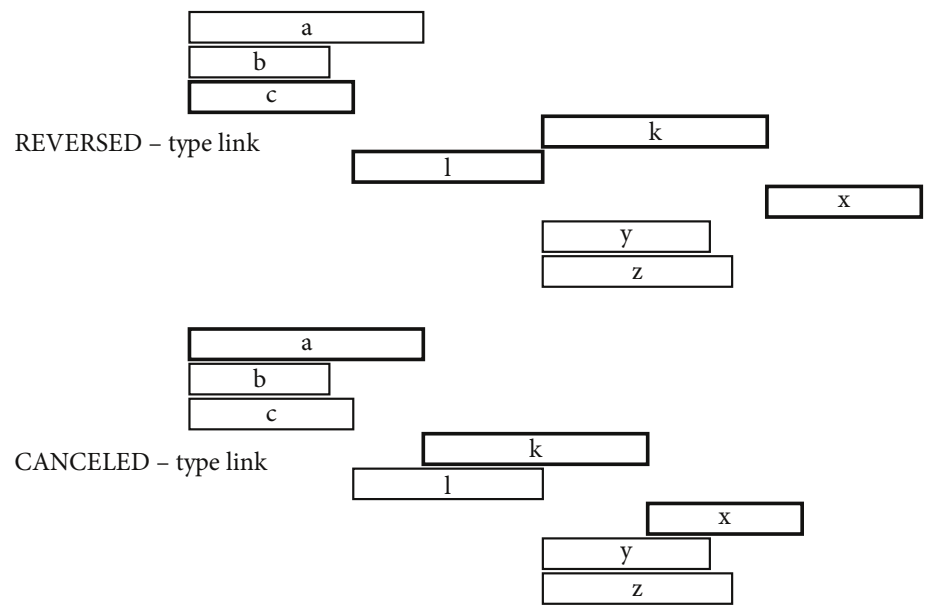

Fig. 1. Example of a project with a soft precedence relation $(k, l):$ a) project schedule before weakening; b) after weakening 
On the one hand, introducing these additional arcs increases complexity of the model. On the other hand, this approach, though laborious, makes it possible to reduce the number of relations - as all the predecessors of activity $k$ should be also defined as predecessors of $l$ and all the successors of $l$ should be declared successors of $k$. Introducing additional arcs makes it possible to start some activities earlier (after weakening the relation) than in the initial schedule and increases the potential to reduce project duration.

For each activity (except for dummy start and finish nodes) $j \in V$, a set $M_{j}$ of possible organizational and technological variants (modes) is defined. Each mode $m \in M_{j}$, is described by the following parameters: $t_{j, m} \in N$ - duration of the activity and $k_{j, m} \in R^{+}$- cost of the activity. A decision which mode is to be implemented is modeled by means of a binary variable $x_{j, m} \in\{0,1\}$. The variable assumes value of 1 if the activity is to be executed in mode $m$, and equals 0 in other cases.

For any pair of activities $(i, j) \in S$, variables $y_{i, j} \in\{0,1\}$ and $z_{i, j} \in\{0,1\}$, defined for $\forall(i, j) \in S R$ and $\forall(i, j) \in S C$ respectively, have been introduced to model "weakened" or "unweakened" character of relations between activities. If a relation $(i, j)$ has not been weakened, and the activity $j$ cannot start before the activity $i$ has been finished, this variables assume values of 0 . The variables equal 1 in the following cases:

1. $y_{i, j}=1$ for REVERSED-type links, where activities are allowed to run in reversed order: activity $j$ will finish before activity $i$ has started,

2. $z_{i, j}=1$ for CANCELED type links, where a link between activities can be canceled, so $j$ may be allowed to start before $i$ has been finished.

Exercising the option of weakening the originally specified precedence relation between activities $i$ and $j,(i, j) \in S$, will carry a penalty $k_{(i, j)}>0$ e.g. related with additional works. Let $d_{l}^{(i, j)}$ represent the duration of additional works; additional works (with duration $d_{l}^{(i, j)}>0$ and / or cost $k_{(i, j)}>0$ ) concern the specific activity $l$ (or activities) and are caused by weakening a particular relation between activities $i$ and $j,(i, j) \in S$. The remaining values of $d_{l}^{(i, j)}$ and $k_{(i, j)}$ equal 0 . The decision making process is aimed at selecting variants of activities and establish $s_{j} \forall j \in V$ - start times of activities in such a way that the total cost of a project is not going to rise beyond the allowed budget $K$, and the total project duration $T$ is minimal.

The mathematical model of this problem (a mixed linear-integer model) takes the following form:

$$
\begin{gathered}
\min T=s_{n}+D_{n}, \\
D_{i}=\sum_{m \in M_{i}} t_{i, m} x_{i, m}+\sum_{(k, l) \in S R} d_{i}^{(k, l)} y_{k, l}+\sum_{(k, l) \in S C} d_{i}^{(k, l)} z_{k, l}, \quad \forall i \in V, \\
\sum_{m \in M_{j}} x_{j, m}=1, \quad \forall j \in V, \\
s_{1}=0, \\
s_{j} \geq s_{i}+D_{i}, \quad \forall(i, j) \in H,
\end{gathered}
$$




$$
\begin{gathered}
C y_{i, j}+s_{j} \geq s_{i}+D_{i}, \quad \forall(i, j) \in S R, \\
C z_{i, j}+s_{j} \geq s_{i}+D_{i}, \quad \forall(i, j) \in S C, \\
s_{j}+D_{j} \leq s_{i}+C\left(1-y_{i, j}\right), \quad \forall(i, j) \in S R, \\
s_{j} \leq s_{i}+D_{i}+C\left(1-z_{i, j}\right), \quad \forall(i, j) \in S C, \\
\sum_{j \in V} \sum_{m \in M_{j}} k_{j, m} x_{j, m}+\sum_{(i, j) \in S R} k_{(i, j)} y_{i, j}+\sum_{(i, j) \in S C} k_{(i, j)} z_{i, j} \leq K, \\
s_{j} \geq 0, \quad \forall j \in V, \\
x_{j, m} \in\{0,1\}, \quad \forall j \in V, \forall m \in M_{j}, \\
y_{i, j} \in\{0,1\}, \quad \forall(i, j) \in S R, \\
z_{i . j} \in\{0,1\}, \quad \forall(i, j) \in S C,
\end{gathered}
$$

where: $V=\{0,1,2, \ldots, n\}-$ set of activities; $E \subset V \times V$ - set of precedence relations between activities; $H$ - set of hard relations; $S$ - set of soft relations; $M_{j}$ - set of possible organizational and technological variants (modes) of activity $j \in V ; t_{j, m} \in N$ - duration of the activity $j$ realized in its mode $m \in M_{j} ; k_{j, m} \in R^{+}$- cost of activity $j$ realized in its mode $m \in M_{j}$; $x_{j, m} \in\{0,1\}$ - binary variable modeling decision of choosing one of activity options; the variable assumes value of 1 if the activity is to be executed by means of the mode $m$, and equals 0 in other cases; $y_{i, j} \in\{0,1\}$ - binary variable representing "weakened" or "unweakened" character of REVERSED-type relations between activities; this variable assumes a value of 0 if a relation $(i, j)$ has not been weakened, and 1 in the other case; $z_{i, j} \in\{0,1\}$ - binary variable representing "weakened" or "unweakened" character of CANCELED-type relations between activities; this variable assumes a value of 0 if a relation $(i, j)$ has not been weakened, and 1 in the other case; $k_{(i, j)}$ - penalty for weakening a relation between activities $i$ and $j$, i.e. cost of additional works caused by weakening a specified relation; $d_{l}^{(i, j)}$ - duration of additional works; additional works concern activity $l$ and are caused by weakening a relation between activities $i$ and $j ; K$ - project budget; $T$ - project duration; $s_{j}$ - activity $j$ start time; $C$ - an arbitrarily large constant.

The objective function (1) minimizes the total project duration. Equation (2) determines duration $D_{i}$ of an activity $i$ - it has been introduced as an auxiliary formula to simplify the formulas (1) and (5)-(9). According to condition (3) each activity can be executed in only one way - as selected from available options. Execution of the first activity of the project (i.e. a activity that has no predecessors) starts at the moment 0 (4). The project cost may not exceed the budget (10). Condition (5) defines the successors' start dates as "not earlier than their predecessors have finished (for hard relations). Similarly, conditions (6)-(9) define start times of activities of the pairs connected by soft relations. $C$ is an arbitrarily assumed, 
sufficiently large constant. In the case that $y_{i, j}=0$ or $z_{i, j}=0$ for $(i, j) \in S$, i.e. the soft precedence relation between activities $i$ and $j$ has not been weakened, conditions (6) and (7) assume the same form as (5), but conditions (8) and (9) are met regardless of start times of activities $i$ and $j$. In the other case, conditions (6) and (7) are always fulfilled, and the start time of the activity $j$ is to be calculated from one of the conditions (8) or (9), depending on the type of soft precedence.

The successive steps of the proposed scheduling procedure are shown in Figure 2.

\section{Computational complexity of the model and proposition of solving methods}

The proposed mathematical formulation of the problem is an extension of the discrete timecost tradeoff problem of which the computational complexity was studied by De et al. (1995). The computational complexity of searching for exact solution grows as an exponential function of the problem size. It follows that the search for algorithms that are both exact and formally

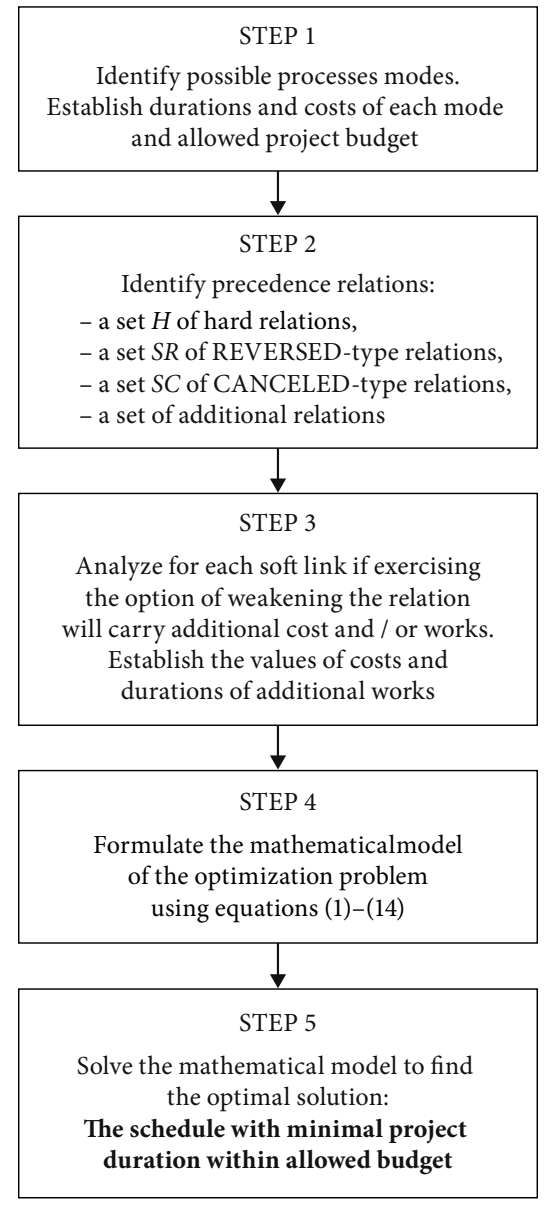

Fig. 2. Proposed scheduling procedure 
efficient is most difficult and that one should instead search for effective procedures (such as exact procedures based on modular network decomposition, or heuristics / metaheuristics which generally produce close-to-optimal solutions in reasonable time). Identification of such procedures would make it viable to include a time-cost analysis with soft logic feature in standard project management software packages. De et al. (1995) suggested a possibility to use genetic heuristics (metaheuristics) based on Artificial Intelligence concepts. Such heuristics, e.g. genetic search algorithms, have recently been used for solving bicriteria problems for realistic project sizes (for example see Jaskowski, Sobotka 2006).

The problem defined above may be divided into two sub-problems to be solved in parallel. The first and major question is formulated as follows: how to choose the variants (modes) of activities and decide if the option of weakening the originally specified precedence relation between activities is to be exercised? The solution with minimal project duration can be searched for by means of genetic search algorithm. Values of the variables $x_{j, m}, y_{i, j}$ and $z_{i, j}$ for each activity and its mode and each soft precedence relation would be then encoded in chromosomes. For each feasible solution generated in the algorithm, the project duration has to be calculated to assess its fitness. It is necessary to find the schedule of minimal project duration with respect to encoded precedence relations and activities' modes. Therefore, the second of the two sub-problems is to establish activities' start times in a way that minimizes project duration. The establishment of project schedule will be done by the use of standard CPM procedure. This approach to solving the problem would enable the planner to find quasi optimal solutions with CPU complexity being lower than in the case of exact mixed linear algorithms.

\section{Example}

The proposed method of reducing construction project duration is illustrated by an example a schedule of finishing works in a residential building. Figure 3 presents the network model (activity on node) with 14 activities (finishing works) and one dummy end node.

The data describing activities are collected in Table 1 (activity number, duration and cost), including options of some of the activities, if applicable. Costs are given in PLN (Polish currency, PLN 1 = USD 0.5).

There are usually a number of possibilities to change the construction works' sequence and to do conduct works in parallel. Four of the activities in the example were assumed to have the option of two modes of operation each, and there are 5 soft precedence relations in the set $S$. The example uses only one type of soft logic, REVERSED, that allows reversing the order of activities (because of the limited building space, the parallel running of activities is not allowed).

Soft links join the following pairs of activities:

- plastering (activity 2 ) and placing screeds (activity 5),

- tiling (activity 8) and painting in bathrooms and kitchens (activity 10),

- painting rooms (activity 7) and painting bathrooms and kitchens (activity 10) at one crew of painters available,

- painting rooms (activity 7) and laying wooden floors in the rooms (activity 9), 
- laying wooden floors in the rooms (activity 9) and fitting cupboards in kitchens (activity 13) (due to layout of flats and disturbance caused by crews carrying cupboard elements these works should not run in parallel).

Nine additional precedence relations have been identified and added to the project network. Two of them are described below:

- If wooden floors (activity 9) were to be finished before paining rooms (activity 7), the floors can be started immediately after plastering (activity 2 ) - there is no need to wait for the plasters to dry.

- If painting kitchens and bathrooms (activity 10) was to be done before painting rooms (activity 7), an additional link would be required to allow electric fittings (activity 12) to be fixed after walls and ceilings have been painted (so electric fittings follow activities 7 and 10).

Table 2 lists costs and durations of additional works. They are going to be necessary in the following cases:

- when screeds (activity 5) are to be made before plastering (activity 2), as the screeds need to be covered to prevent staining with plaster mortar,

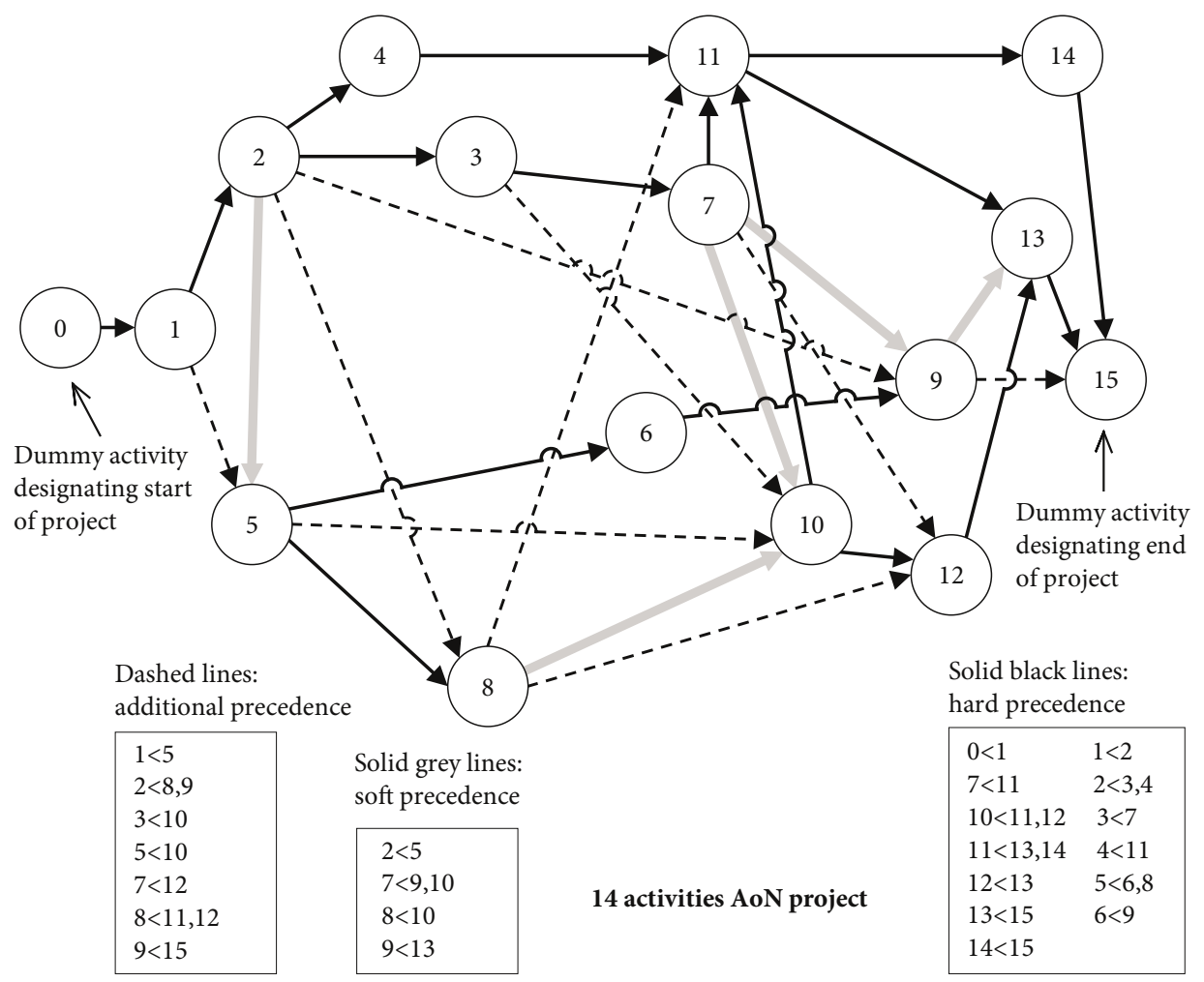

Fig. 3. Network model of finishing works (example) 
- when wooden floors are to be fixed (activity 9) before rooms are painted (activity 7) - floor covering is needed,

- when kitchens and bathrooms are to be painted (activity 10) before tiling (activity 8 ) - some local repainting is to be expected.

Table 1. Activities durations and costs (Example)

\begin{tabular}{clccc}
\hline $\begin{array}{c}\text { Activity } \\
\text { number }\end{array}$ & \multicolumn{1}{c}{$\begin{array}{c}\text { Name } \\
\text { of activity }\end{array}$} & Variant & $\begin{array}{c}\text { Duration } \\
{[\text { days }}\end{array}$ & $\begin{array}{c}\text { Cost } \\
{[\text { PLN] }}\end{array}$ \\
\hline 1 & services: plumbing, electrical, heating & I & 24 & 48000 \\
\hline 2 & plastering & I & 20 & 24000 \\
\hline & & II & 30 & 18000 \\
\hline 3 & technological break & I & 7 & 0 \\
\hline 4 & gas piping & I & 5 & 11500 \\
\hline 5 & screed & I & 10 & 12000 \\
\hline & & II & 14 & 10200 \\
\hline 6 & technological break & I & 21 & 0 \\
\hline 7 & painting: walls and ceilings & I & 5 & 2500 \\
\hline 8 & tiling & I & 12 & 15800 \\
\hline 9 & & II & 15 & 13600 \\
\hline & wooden floor & I & 10 & 10000 \\
\hline 10 & painting: kitchens and bathrooms & II & 6 & 19000 \\
\hline 11 & waterproof painting & I & 2 & 800 \\
\hline 12 & electrical fittings & I & 2 & 500 \\
\hline 13 & fitted cupboards (kitchen) & I & 2 & 1700 \\
\hline 14 & sanitary appliances & I & 3 & 20000 \\
\hline 15 & & I & 3 & 8000 \\
\hline & & II & 2 & 10000 \\
\hline & & I & 0 & 0 \\
\hline
\end{tabular}

Table 2. Non-zero costs and durations of additional works caused by weakening a relation between activity $i$ and $j$

\begin{tabular}{cccccc}
\hline $\begin{array}{c}\text { Number of activity } \\
l \text { with additional } \\
\text { works }\end{array}$ & Numbers of activities: & & $\begin{array}{c}\text { Duration of } \\
\text { additional works } \\
(i, j)\end{array}$ & $\begin{array}{c}\text { Cost of additional } \\
\text { works } \\
\text { [days] }\end{array}$ & $\begin{array}{c}k_{(i, j)} \\
{[\text { PLN] }}\end{array}$ \\
\cline { 2 - 3 } & 2 & $j$ & 5 & $d_{5}^{(2,5)}=2$ & $k_{(2,5)}=200$ \\
\hline 5 & 7 & 9 & $d_{9}^{(7,9)}=1$ & $k_{(7,9)}=70$ \\
\hline 10 & 8 & 10 & $d_{10}^{(8,10)}=1$ & $k_{(8,10)}=50$ \\
\hline
\end{tabular}


The following versions of the model were analyzed:

Series I - the model allows for all identified feasible variants of construction methods and organization of activities, and for weakening the soft relations;

Series II - the model comprises only variants of activities identified to be of longest duration and lowest costs, and allows for weakening the soft relations;

Series III - the model comprises only variants of shortest duration and highest cost and allows for weakening the soft relations;

Series IV - the model comprises only variants of activities identified to be of longest duration and lowest costs, and does not allow for weakening the soft relations;

Series $\mathrm{V}$ - the model comprises only variants of shortest duration and highest cost and does not allow for weakening the soft relations;

Series VI - the model comprises all variants of methods and organization of the activities, and does not allow for weakening the soft relations.

Each series was then analyzed in search for non-dominated solutions of the bi-criteria problem - the time-cost tradeoff. These solutions were schedules composed of certain activity variants and a certain sequence of activities under constraints defined for each series. This way, there existed no other solution (schedule) that was, at the same time, of lower cost and shorter duration. The mathematical model was solved by means of lp_solve (Open source Mixed-Integer Linear Programming system, version 5.1.0.0 of 1 May 2004, by Michel Berkelaar, Kjell Eikland, Peter Notebaert GNU LGPL). The analysis of each series was repeated several times for various assumed budgets. Each time, a solution of minimal duration and cost within budget was found. From these solutions, the non-dominated ones were selected and presented in Figure 4 for each series.

The pairwise comparisons (I-VI, III-V, II-IV) of the results supported the thesis that applying soft logic to scheduling provides more flexibility in reducing project duration. This was most apparent at comparing Series II with Series IV, and Series III with Series V, as the activities were of the same cost and duration. Alternative solutions from Series II and III also support the thesis: in both of them three solutions were obtained despite the fact that activities were executed in a fixed way (no activity modes considered). For each solution of Series IV there existed a solution of Series I better in terms of time and cost - and this

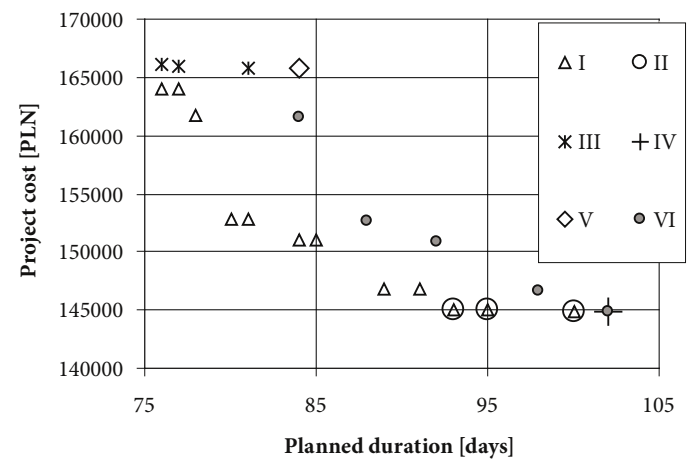

Fig. 4. Results of calculations for each series (non-dominated solutions) 
was due to applying soft precedence relations. Therefore, by permitting the relations to be weakened (using soft logic) and by analyzing options of activities, it was possible to find all non-dominated solutions of the bicriteria problem.

The shortest project duration occurred to be 76 days (Series I and Series III). The corresponding project cost is PLN 166070 (Series III) and PLN 164070 (Series I), and the difference in cost results from the fact that sanitary appliances (activity 14) could be completed PLN 2000 cheaper and only 1 day longer (difference between activity 14 modes) without affecting the total project duration. The schedule of the latter solution is presented in Figure 5.

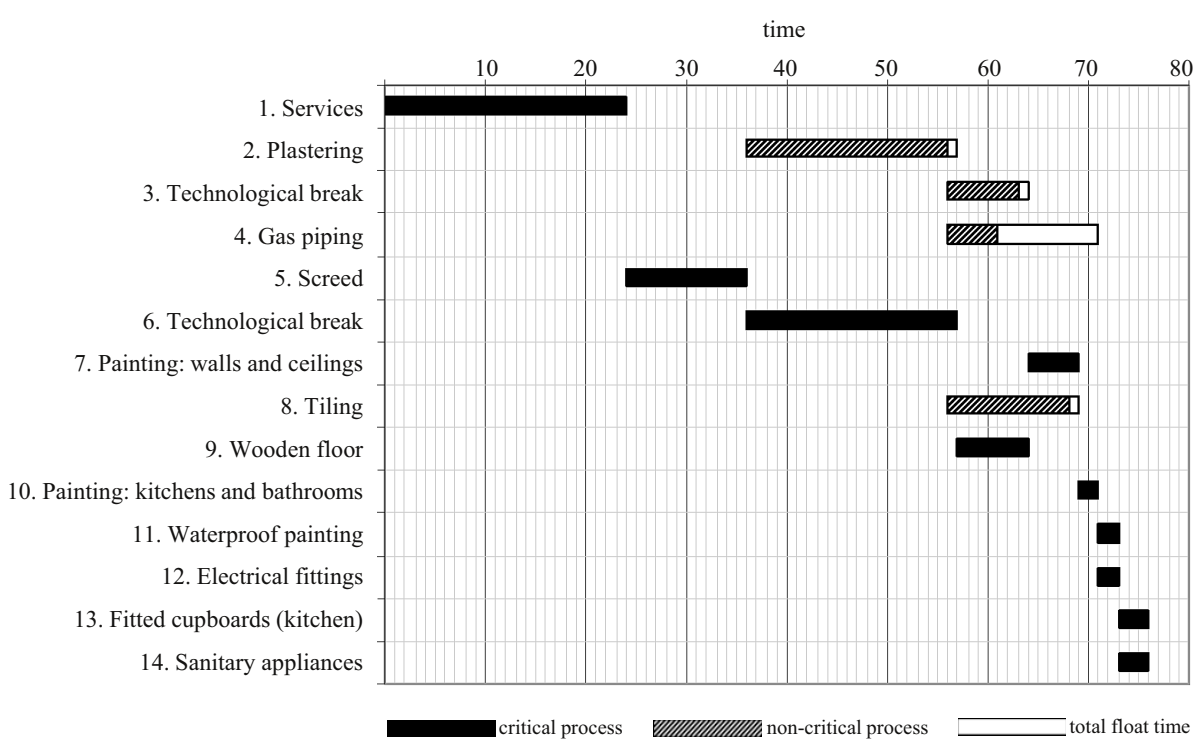

Fig. 5. Bar chart of the schedule with project cost PLN 164070 and minimal project duration 76 days (Series I)

The lowest project cost of PLN 144800 was obtained for Series II, IV and VI by their minimal duration of 102 days. In Series I, the solution of the same cost was by 2 days shorter. Allowing for all possible variants of activities and weakening the soft relations (Series I) enabled the planner to reduce project duration by 2 days.

Series I have the greatest potential of reducing project duration due to allowing for the greatest number of variants and the highest flexibility of activity sequencing.

In the "shortest" schedules, obtained for Series I, II and III, the relations between activities 2 and 5, and between activities 7 and 9 were weakened (this means that in order to cut project time, screeds should be made before plasters, and wooden floors before painting). In the "cheapest" schedules, obtained for Series I, II and III, the relation between activities 9 and 13 was weakened (so, to cut costs, kitchen cupboards should be fitted in before wooden floors are laid). Of course, the above "physical" interpretation is example-specific and the outcome cannot be transferred to finishing works projects in general. 


\section{Conclusions}

Introducing soft logic into network models of projects increases the number of feasible solutions, expands the range of values of optimization criteria and allows the planner to find a solution of reduced duration without compromising the project budget. It is important for both project owners and contractors. The results of calculations presented above, despite limited scope of the analysis, support the authors' thesis: using soft relations in modeling projects increases flexibility of scheduling under pressure to reduce the total duration of a project.

Shortening of the project duration leads to increase total floats of project activities, so its start times can be scheduled later without affecting the contractual due date. This enables the planner to find better resource utilization profile and increases the probability of not exceeding the project due date. The aim of our work was to indicate the benefits (in terms of project duration shortening) of incorporating soft precedence relations into the model. This study proposes a mixed linear integer programming model of minimizing the project duration by considering the use of soft links. It enables finding optimal schedules in terms of project duration, and may be applied to creating both initial baseline schedules and schedule updates. This is a considerable asset in comparison to previous models that rest mainly upon heuristic procedures. However, as the practical problem is complex, the paper proposes only a concept of solving procedure. The authors are working to develop the method further using evolutionary algorithms to make it useful for planning large and complex projects. The proposed model that uses a new type of activity relations can be, in the opinion of the authors, adopted also by the existing computer systems in their future development.

The model considers additional cost and / or works connected with changing the processes' sequence. It also and enables analyzing the time-cost trade-off to select the most efficient way of project duration reduction - by considering the set of Pareto non-dominated solutions, generated by solving proposed problem formulation for a various allowed budgets / project costs increase variants.

\section{References}

Biruk, S.; Jaskowski, P. 2008. Simulation modelling construction project with repetitive tasks using Petri nets theory, Journal of Business Economics and Management 9(3): 219-226.

http://dx.doi.org/10.3846/1611-1699.2008.9.219-226

Boguslauskas, V.; Adlyte, R. 2010. Evaluation of criteria for the classification of enterprises, Inzinerine Ekonomika - Engineering Economics 21(2): 119-127.

Chassiakos, A. P.; Sakellaropoulos, S. P. 2005. Time-cost optimization of construction projects with generalized activity constraints, Journal of Construction Engineering and Management 131(10): 1115-1124. http://dx.doi.org/10.1061/(ASCE)0733-9364(2005)131:10(1115)

De, P.; Dunne, E. J.; Ghosh, J. B.; Wells, C. E. 1995. The discrete time-cost tradeoff problem revisited, European Journal of Operational Research 81(2): 225-238. http://dx.doi.org/10.1016/0377-2217(94)00187-H

Elmaghraby, S. E.; Salem, A. 1982. Optimal project compression under quadratic cost functions, Applications of Management Science 2: 1-39.

Elmaghraby, S. E.; Salem, A. 1984. Optimal linear approximation in project compression, IIE Transactions 16(4): 339-347. http://dx.doi.org/10.1080/07408178408975253 
Enshassi, A.; Arain, F.; Al-Raee, S. 2010. Causes of variation orders in construction projects in the Gaza Strip, Journal of Civil Engineering and Management 16(4): 540-551. http://dx.doi.org/10.3846/jcem.2010.60

Falk, J. E.; Horowitz, J. L. 1972. Critical path problems with concave cost-time curves, Management Science 19(4): 446-455. http://dx.doi.org/10.1287/mnsc.19.4.446

Fan, S. L.; Tserng, H. P. 2006. Object-oriented scheduling for repetitive projects with soft logics, Journal of Construction Engineering and Management 132(1): 35-48. http://dx.doi.org/10.1061/(ASCE)0733-9364(2006)132:1(35)

Fan, S. L.; Tserng, H. P.; Wang, M. T. 2003. Development of an object-oriented scheduling model for construction projects, Automation in Construction 12(3): 283-302. http://dx.doi.org/10.1016/S0926-5805(02)00092-4

Fulkerson, D. R. 1961. A network flow computation for project cost curves, Management Science 7(2): 167-178. http://dx.doi.org/10.1287/mnsc.7.2.167

Ginevičius, R.; Zubrecovas, V. 2009. Selection of the optimal real estate investment project basing on multiple criteria evaluation using stochastic dimensions, Journal of Business Economics and Management 10(3): 261-270. http://dx.doi.org/10.3846/1611-1699.2009.10.261-270

Harris, R. B.; Ioannou, P. G. 1998. Scheduling projects with repeating activities, Journal of Management in Engineering 124(4): 269-276.

Hola, B. 2010. Methodology of hazards identification in construction work course, Journal of Civil Engineering and Management 16(4): 577-585. http://dx.doi.org/10.3846/jcem.2010.64

Jaskowski, P.; Biruk, S. 2011. The method for improving stability of construction project schedules through buffer allocation, Technological and Economic Development of Economy 17(3): 429-444. http://dx.doi.org/10.3846/20294913.2011.580587

Jaskowski, P.; Biruk, S.; Bucoń, R. 2010. Assessing contractor selection criteria weights with fuzzy AHP method application in group decision environment, Automation in Construction 19(2): 120-126. http://dx.doi.org/10.1016/j.autcon.2009.12.014

Jaskowski, P.; Sobotka, A. 2006. Multicriteria construction project scheduling method using evolutionary algorithm, Operational Research - An International Journal 6(3): 283-397.

Kahraman, C.; Kaya, İ. 2010. Investment analyses using fuzzy probability concept, Technological and Economic Development of Economy 16(1): 43-57. http://dx.doi.org/10.3846/tede.2010.03

Kaplinski, O.; Janusz, L. 2006. Three phases of multifactor modelling of construction processes, Journal of Civil Engineering and Management 12(2): 127-134. http://dx.doi.org/10.3846/tede.2010.22

Kapliński, O.; Tamošaitienè, J. 2010. Game theory applications in construction engineering and management, Technological and Economic Development of Economy 16(2): 348-363.

Karlowski, A.; Paslawski, J. 2008. Monitoring of construction processes in the variable environment, Technological and Economic Development of Economy 14(4): 503-517. http://dx.doi.org/10.3846/1392-8619.2008.14.503-517

Kelley, J. E. 1961. Critical path planning and scheduling: mathematical basis, Operations Research 9: 296-320. http://dx.doi.org/10.1287/opre.9.3.296

Kheirkhah, A. S.; Esmailzadeh, A.; Ghazinoory, S. 2009. Developing strategies to reduce the risk of hazardous materials transportation in Iran using the method of fuzzy SWOT analysis, Transport 24(4): 325-332. http://dx.doi.org/10.3846/1648-4142.2009.24.325-332

Klimov, R.; Merkuryev, Y. 2008. Simulation model for supply chain reliability evaluation, Technological and Economic Development of Economy 14(3): 300-311.

http://dx.doi.org/10.3846/1392-8619.2008.14.300-311 
Koo, B.; Fischer, M.; Kunz, J. 2007. A formal identification and re-sequencing process for developing sequencing alternatives in CPM schedules, Automation in Construction 17(1): 75-89. http://dx.doi.org/10.1016/j.autcon.2007.03.005

Lamberson, L. R.; Hocking, R. R. 1970. Optimum time compression in project scheduling, Management Science 16: 597-606. http://dx.doi.org/10.1287/mnsc.16.10.B597

Liberatore, M. J.; Pollack-Johnson, B. 2006. Extending project time-cost analysis by removing precedence relations and task streaming, International Journal of Project Management 24(6): 529-535. http://dx.doi.org/10.1016/j.ijproman.2006.04.004

Lin, M.-Ch.; Tserng, H. P.; Ho, S.-P.; Young, D.-L. 2011. Developing a construction-duration model based on a historical dataset for building project, Journal of Civil Engineering and Management 17(4): 529-539. http://dx.doi.org/10.3846/13923730.2011.625641

Maheswari, J. U.; Varghese, K.; Sridharan, T. 2006. Application of dependency structure matrix for activity sequencing in concurrent engineering projects, Journal of Construction Engineering and Management 132(5): 482-490. http://dx.doi.org/10.1061/(ASCE)0733-9364(2006)132:5(482)

Manik, A.; Gopalakrishnan, K.; Singh, A.; Yan, S. 2008. Neural networks surrogate models for simulating payment risk in pavement construction, Journal of Civil Engineering and Management 14(4): 235-240. http://dx.doi.org/10.3846/1392-3730.2008.14.22

Moussourakis, J.; Haksever, C. 2004. Flexible model for time/cost tradeoff problem, Journal of Construction Engineering and Management 130(3): 307-314. http://dx.doi.org/10.1061/(ASCE)0733-9364(2004)130:3(307)

Paslawski, J. 2008. Flexibility approach in construction process engineering, Technological and Economic Development of Economy 14(4): 518-530. http://dx.doi.org/10.3846/1392-8619.2008.14.518-530

Peldschus, F. 2008. Experience of the game theory application in construction management, Technological and Economic Development of Economy 14(4): 531-545.

http://dx.doi.org/10.3846/1392-8619.2008.14.531-545

Perera, B. A. K. S.; Dhanasinghe, I.; Rameezdeen, R. 2009. Risk management in road construction: the case of Sri Lanka, International Journal of Strategic Property Management 13(2): 87-102. http://dx.doi.org/10.3846/1648-715X.2009.13.87-102

Pridotkiene, J.; Dapkus, M. 2011. The model to evaluate risk factors of exporter-provided trade credit, Inzinerine Ekonomika - Engineering Economics 22(5): 477-484.

Reda, R. M. 1990. RPM: repetitive project modeling, Journal of Construction Engineering and Management 116(2): 316-330. http://dx.doi.org/10.1061/(ASCE)0733-9364(1990)116:2(316)

Russel, A. D.; Wong, W. C. M. 1993. New generation of planning structures, Journal of Construction Engineering and Management 119(2): 196-214. http://dx.doi.org/10.1061/(ASCE)0733-9364(1993)119:2(196)

Sakellaropoulos, S.; Chassiakos, A. P. 2004. Project time-cost analysis under generalised precedence relations, Advances in Engineering Software 35(10-11): 715-724. http://dx.doi.org/10.1016/j.advengsoft.2004.03.017

Sapkauskiene, A.; Leitoniene, S. 2010. The concept of time-based competition in the context of management theory, Inzinerine Ekonomika - Engineering Economics 21(2): 205-213.

Shevchenko, G.; Ustinovichius, L.; Andruškevičius, A. 2008. Multi-attribute analysis of investments risk alternatives in construction, Technological and Economic Development of Economy 14(3): 428-443. http://dx.doi.org/10.3846/1392-8619.2008.14.428-443

Siemens, N. 1971. A simple CPM time/cost trade-off algorithm, Management Science 17(6): 354-363. http://dx.doi.org/10.1287/mnsc.17.6.B354

Tamimi, S.; Diekmann, J. 1988. Soft logic in network analysis, Journal of Computing in Civil Engineering 2(3): 289-300. http://dx.doi.org/10.1061/(ASCE)0887-3801(1988)2:3(289) 
Vlasenko, O.; Kozlov, S. 2009. Choosing the risk curve type, Technological and Economic Development of Economy 15(2): 341-351. http://dx.doi.org/10.3846/1392-8619.2009.15.341-351

Wang, W.-Ch. 2005. Impact of soft logic on the probabilistic duration of construction projects, International Journal of Project Management 23(8): 600-610. http://dx.doi.org/10.1016/j.ijproman.2005.05.008

Yang, I.-T. 2007. Performing complex project crashing analysis with aid of particle swarm optimization algorithm, International Journal of Project Management 25(6): 637-646. http://dx.doi.org/10.1016/j.ijproman.2006.11.001

Zavadskas, E. K.; Turskis, Z.; Tamošaitienè, J. 2010c. Risk assessment of construction projects, Journal of Civil Engineering and Management 16(1): 33-46. http://dx.doi.org/10.3846/jcem.2010.03

Zavadskas, E. K.; Turskis, Z.; Ustinovichius, L.; Shevchenko, G. 2010b. Attributes weights determining peculiarities in multiple attribute decision making methods, Inzinerine Ekonomika - Engineering Economics 21(1): 32-43.

Zavadskas, E. K.; Vilutiene, T.; Turskis, Z.; Tamošaitiene, J. 2010a. Contractor selection for construction works by applying SAW-G and Topsis grey techniques, Journal of Business Economics and Management 11(1): 34-55. http://dx.doi.org/10.3846/jbem.2010.03

Zheng, D. X. M.; Ng, S. T.; Kumaraswamy, M. M. 2004. Applying a genetic algorithm-based multiobjective approach for time-cost optimization, Journal of Construction Engineering and Management 130(2): 168-176. http://dx.doi.org/10.1061/(ASCE)0733-9364(2004)130:2(168)

Piotr JASKOWSKI. Ph.D. Eng. at Lublin University of Technology, Poland. He is the Head of the Group of Construction and Investments Processes Engineering working in the Construction Institute. He is a member of the Section of the Engineering of Construction Projects in Civil Engineering Committee of Polish Academy of Science. He is the member of EURO Working Group "OR in Sustainable Development and Civil Engineering" and International Group on Reliability. His research interests include the organization and modeling of construction processes, construction projects scheduling, and optimization techniques.

Anna SOBOTKA. DSc. (Eng), Assoc. Prof., Department of Geomechanics, Construction and Geotechnics Faculty of Mining and Geoengineering, AGH University of Science and Technology in Cracow, Poland. Graduate Warsaw University of Technology. Academic degrees: Ph.D. in construction from Warsaw University of Technology and D.Sc. from Poznan University of Technology (2001). Author of about 150 scientific articles. Research interests: construction technology and organization, project management, construction logistics management and sustainable development in construction, properties management. 